Review began 08/31/2021 Review ended 09/04/2021 Published 09/08/2021

๑) Copyright 2021

Adhikari et al. This is an open access article distributed under the terms of the Creative Commons Attribution License CC-BY 4.0 . which permits unrestricted use, distribution, and reproduction in any medium, provided the original author and source are credited.

\section{Use of Tocilizumab May Avoid the Need of Invasive Ventilation}

\author{
Anurag Adhikari ${ }^{1}$, Ayusha Poudel ${ }^{1}$, Oshna Pandey ${ }^{2}$, Barun B. Aryal ${ }^{3}$, Bibek Dhungana ${ }^{4}$ \\ 1. Intensive Care Unit, Nepal Korea Friendship Municipality Hospital, Madhyapur Thimi, NPL 2. School of Medicine, \\ Patan Academy of Health Sciences, Kathmandu, NPL 3. Emergency Medicine, BP Smriti Hospital, Kathmandu, NPL 4. \\ Internal Medicine, KIST Medical College, Lalitpur, NPL
}

Corresponding author: Anurag Adhikari, a.adhikarianu@gmail.com

Categories: Internal Medicine, Infectious Disease, Pulmonology Keywords: covid-19, sars-cov-2, cytokines, tocilizumab, ventilation

\title{
Introduction
}

Coronavirus disease 2019 (COVID-19) is a disease condition caused by the severe acute respiratory syndrome coronavirus 2 (SARS-CoV-2). It mainly affects the respiratory system. In the early phases of the COVID-19 pandemic, it was found that severe forms of SARS-CoV-2 infection were associated with dysregulated immune response and cytokine storm leading to inflammation of the lungs [1]. Interleukin 6 (IL-6) is a proinflammatory cytokine [2]. It has been hypothesized that pro-inflammatory cytokines like IL-6 play a role in severe illness due to SARS-CoV-2 [3].

Tocilizumab is one of the earliest marketed drugs that targets and blocks the interleukin- 6 receptor [4]. The use of tocilizumab seemed to improve the outcome in hospitalized patients in the early phase of the pandemic [5]. We present a case of a 59-year-old man who presented with severe bilateral COVID-19 pneumonia and was deteriorated to the point where endotracheal intubation was contemplated. However, the use of tocilizumab resulted in recovery, and oxygen supplementation could be weaned gradually.

\section{Case Presentation}

A 53-year-old male was referred to our center with complaints of shortness of breath and fever for three days. A reverse transcription-polymerase chain reaction (RT-PCR) for COVID-19 was performed, which yielded a positive result three days back. His co-morbidity was hypertension for which he was under amlodipine 10 milligrams (mg) orally daily. On presentation, he was neurologically intact and afebrile. However, there was decreased air entry in the bilateral hemithoraces with bilateral basilar crepitation. He was under oxygen supplementation at 15 liters per minute $(\mathrm{L} / \mathrm{min})$ via a face mask with a reservoir bag and his oxygen saturation was maintained at $95 \%$. His D-dimer levels were 230 nanogram per milliliter $(\mathrm{ng} / \mathrm{mL})$ (biological reference interval 0 to $500 \mathrm{ng} / \mathrm{mL}$ ). His metabolic panel was within the normal limits. His chest Xray revealed bilateral infiltrates in the lungs and he was admitted to the intensive care unit with a diagnosis of bilateral COVID-19 pneumonia (Figure 1). He was started on intravenous piperacillin/tazobactam 4.5 grams (gm) thrice daily, intravenous vancomycin $1 \mathrm{gm}$ twice daily, intravenous dexamethasone $6 \mathrm{mg}$ once daily, and subcutaneous enoxaparin $60 \mathrm{mg}$ once daily. 


\section{Cureus}

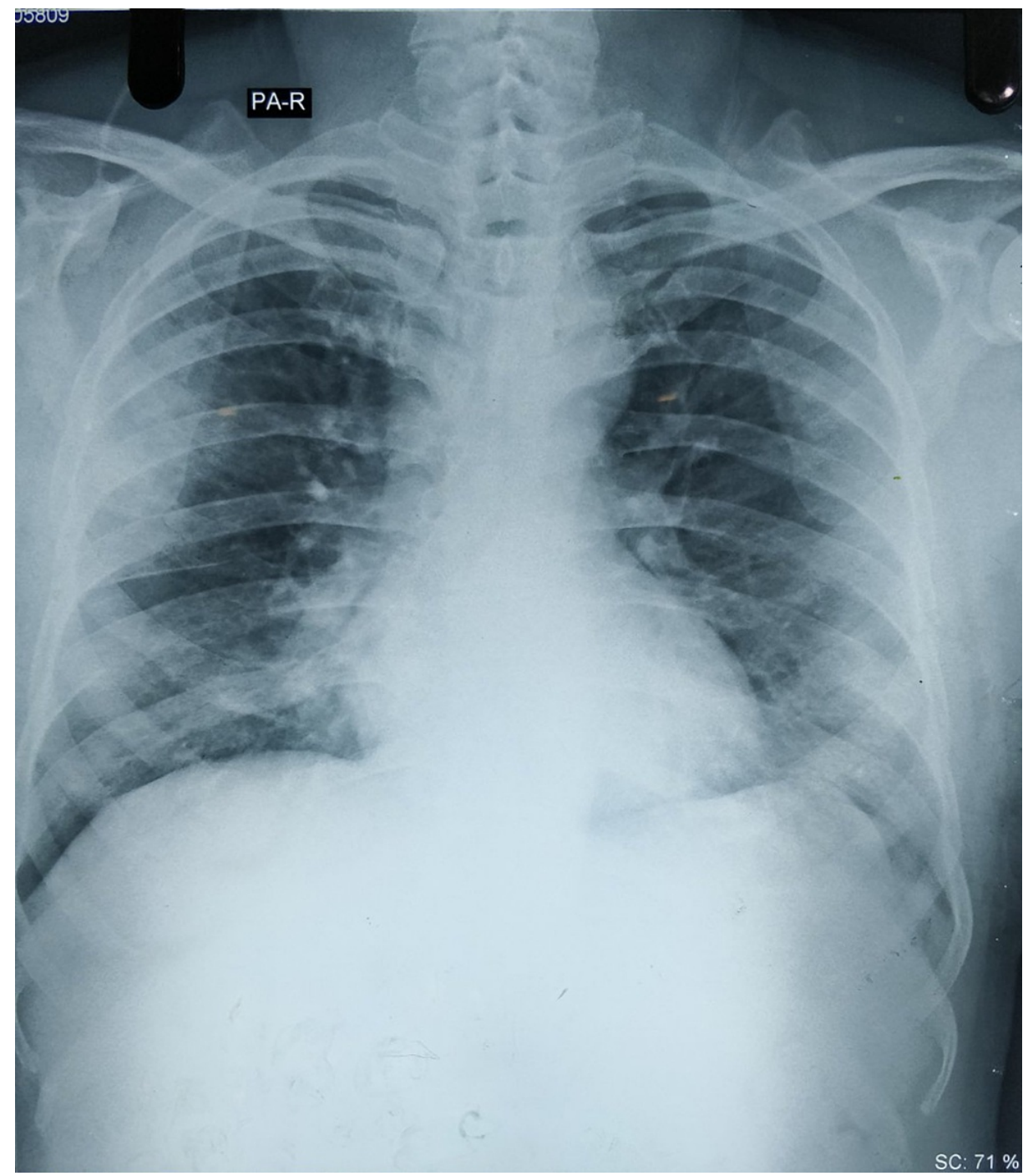

FIGURE 1: Chest X-ray demonstrating bilateral pneumonia.

On the subsequent day, his oxygen saturation began to drop and fluctuated between $93 \%$ and $95 \%$. He began to further deteriorate and his oxygen saturation started to fluctuate around $83 \%$ to $86 \%$. The arterial blood gas (ABG) analysis revealed a potential of hydrogen $(\mathrm{pH})$ of 7.434, partial pressure of arterial oxygen $\left(\mathrm{PaO}_{2}\right)$ of 65 millimeters of mercury ( $\mathrm{mmHg}$ ), partial pressure of arterial carbon dioxide $\left(\mathrm{PaCO}_{2}\right)$ of $29.8 \mathrm{mmHg}$, and bicarbonate level of 21.4 milliequivalents per liter $(\mathrm{mEq} / \mathrm{L})$. He was then initiated on a high-flow nasal cannula (HFNC) with fractional oxygen $\left(\mathrm{FiO}_{2}\right)$ of $90 \%$ and a flow rate of $70 \mathrm{~L} / \mathrm{min}$.

His condition got worse by the day and on the third day of admission, his peripheral oxygen saturation hovered from $81 \%$ to $85 \%$ when placed on $\mathrm{HFNC}$. His ABG reports revealed pH of 7.410, $\mathrm{PaO}_{2}$ of $91 \mathrm{mmHg}$, $\mathrm{PaCO}_{2}$ of $28.8 \mathrm{mmHg}$, and bicarbonate of $19.1 \mathrm{mEq} / \mathrm{L}$. Consideration for the need for endotracheal intubation was made; however, the patient and his relatives were reluctant to provide consent until other therapeutic options were available. The HFNC was supplemented with a reservoir bag with oxygen at 15 $\mathrm{L} /$ min over the cannula to maintain the oxygen saturation over $90 \%$ overnight. His procalcitonin levels were found to be 0.25 nanogram per milliliter $(\mathrm{ng} / \mathrm{mL}$ ) (biological reference range of 0 to $0.5 \mathrm{ng} / \mathrm{mL}$ ) and the interleukin 6 (IL-6) levels were 11.9 picograms per milliliter $(\mathrm{pg} / \mathrm{mL}$ ) (biological reference range of less than 7 $\mathrm{pg} / \mathrm{mL})$.

On the fourth day of admission, non-invasive ventilation was trialed but the patient could not tolerate it. The patient was then kept in a prone position with oxygen supplementation via $\mathrm{HFNC}$ at $\mathrm{FiO}_{2}$ of $80 \%$ and flow rate of $50 \mathrm{~L} / \mathrm{min}$ in addition to a face mask with a reservoir bag providing oxygen at $10 \mathrm{~L} / \mathrm{min}$. A single dose of tocilizumab 400 milligrams (mg) was given intravenously to the patient on the same day after being diluted in 100 milliliters $(\mathrm{mL})$ of $0.9 \%$ normal saline over one hour.

Interestingly, the patient started getting better overnight and his oxygen saturation was maintained with 


\section{Cureus}

HFNC alone. A trial of oxygen supplementation at $\mathrm{FiO}_{2}$ of $60 \%$ with a venturi mask was done but he was unable to maintain the oxygen saturation. The ABG analysis showed pH of $7.44, \mathrm{PaO}_{2}$ of $60 \mathrm{mmHg}, \mathrm{PaCO}_{2}$ of $27.9 \mathrm{mmHg}$, and bicarbonate of $20 \mathrm{mEq} / \mathrm{L}$.

On the fifth day of admission, he showed significant improvement. He was able to maintain peripheral oxygen saturation above $92 \%$ with oxygen supplementation via venturi mask of $60 \%$ when supine and above $64 \%$ when prone. The $\mathrm{ABG}$ analysis revealed $\mathrm{pH}$ of $7.42, \mathrm{PaO}_{2}$ of $80 \mathrm{mmHg}, \mathrm{PaCO}_{2}$ of $28 \mathrm{mmHg}$, and bicarbonate of $18 \mathrm{mEq} / \mathrm{L}$. His chest X-ray also showed improvement (Figure 2).

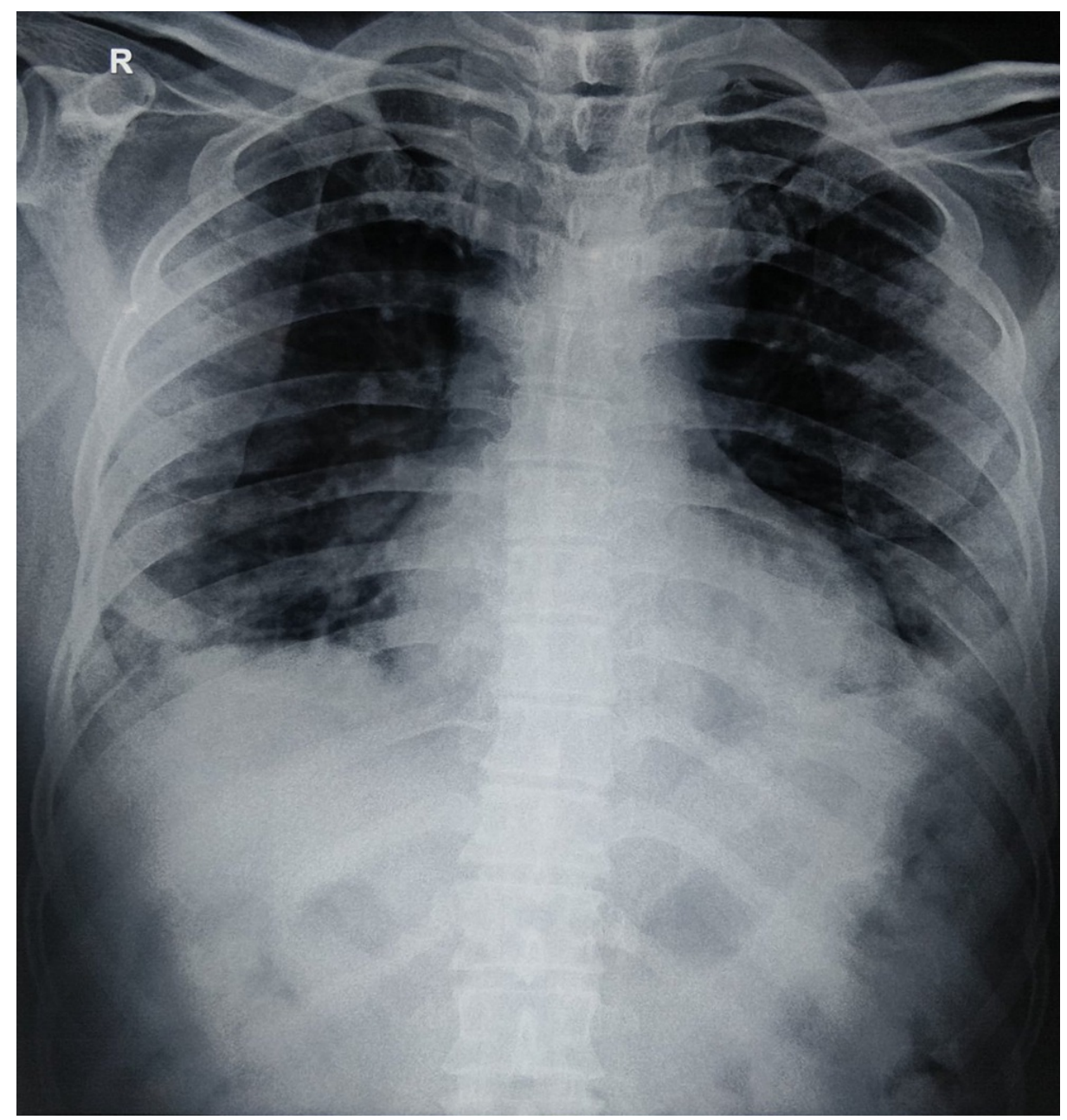

FIGURE 2: Chest X-ray after two days of administration of tocilizumab.

On the following two days, the oxygen supplementation was gradually tapered from $\mathrm{FiO}_{2}$ of $60 \%$ to $31 \%$ via venturi mask. On the 13th day of admission, he was transferred to the ward with oxygen supplementation of $5 \mathrm{~L} / \mathrm{min}$ via nasal prongs.

His laboratory studies during the course of treatment are summarized in Table 1. 


\section{Cureus}

\begin{tabular}{|c|c|c|c|}
\hline Laboratory parameters & At admission & On-shift to ward & Reference range \\
\hline Total leucocyte count & 9,600 & 14,200 & $4,000-11,000$ cells $/ \mathrm{mm}^{3}$ \\
\hline Neutrophils & 93 & 91 & $40 \%-15 \%$ \\
\hline Lymphocytes & 6 & 5 & $20 \%-50 \%$ \\
\hline Eosinophils & 0 & 1 & $1 \%-6 \%$ \\
\hline Monocytes & 1 & 3 & $2 \%-10 \%$ \\
\hline Basophils & 0 & 0 & $0 \%-1 \%$ \\
\hline Hemoglobin & 12.9 & 13.2 & 13-18 gm/dL \\
\hline Platelets & 110,000 & 291,000 & $150,000-400,000$ cells $/ \mathrm{mm}^{3}$ \\
\hline Urea & 23.4 & 26 & $15-45 \mathrm{mg} / \mathrm{dL}$ \\
\hline Creatinine & 1.35 & 1.3 & $0.4-1.4 \mathrm{mg} / \mathrm{dL}$ \\
\hline Sodium & 139 & 139 & $135-146 \mathrm{mEq} / \mathrm{L}$ \\
\hline Potassium & 4.2 & 4.1 & $3.5-5.3 \mathrm{mEq} / \mathrm{L}$ \\
\hline
\end{tabular}

\section{TABLE 1: Laboratory studies of the patient.}

cells $/ \mathrm{mm}^{3}$ : cells per cubic milliliter; gm/dL: gram per deciliter; $\mathrm{mg} / \mathrm{dL}$ : milligram per deciliter; $\mathrm{mEq} / \mathrm{L}$ : milliequivalent per liter.

\section{Discussion}

The severe forms of COVID-19 illnesses have a poor prognosis. The severity of illness with SARS-CoV-2 is found to be correlated with the pro-inflammatory cytokine levels in the plasma [6]. Severe hospitalized patients in a study had an increased level of interleukin 6 (IL-6) [7]. Tocilizumab is a monoclonal antibody against IL- 6 and its use had been well demonstrated for rheumatoid arthritis prior to the pandemic [4]. The role of cytokine storm in severe SARS-CoV-2 infection and elevated IL-6 levels led to the use of tocilizumab for COVID-19 illness. The use of tocilizumab showed benefit in hospitalized COVID-19 patients in China [5]. The subsequent observational study proved that the use of tocilizumab had a mortality benefit in critically ill patients [8]. The Randomized, Embedded, Multifactorial Adaptive Platform Trial for Community-Acquired Pneumonia (REMAP-CAP) demonstrated that tocilizumab had improved outcomes including survival [9].

Randomized controlled trials, however, have not uniformly proven the therapeutic benefit of tocilizumab in COVID-19 patients. A randomized controlled study demonstrated that it reduced the need for progression to mechanical ventilation but had no effect on survival [10]. However, another study showed neither benefit in preventing intubation nor in death for moderately severe hospitalized COVID-19 patients [11]. Another randomized trial in COVID-19 pneumonia patients with $\mathrm{PaO}_{2} / \mathrm{FiO}_{2}$ ratio between 200 and $300 \mathrm{mmHg}$, revealed that tocilizumab had no benefit on disease progression [12].

Consistent with the majority of randomized trials, meta-analyses have been unable to suggest the use of tocilizumab beyond doubt. A similar study could not find the evidence for the use of tocilizumab and recommended the halting of its use until further evidence was available [13]. Another systematic review found the evidence insufficient and advised the use of tocilizumab as an experiment [14]. The United States Food and Drug Administration (FDA) has recently approved tocilizumab for hospitalized patients of age two years and more, who are also receiving corticosteroids and supplemental oxygen in any form [15].

However, Randomised Evaluation of COVID-19 Therapy (RECOVERY) trial has revealed that tocilizumab resulted in improvement of survival as well as other clinical outcomes in hospitalized COVID-19 patients with hypoxia regardless of respiratory support [16]. More studies might be needed to elucidate the actual role of tocilizumab.

Our case was a 59-year-old hypertensive man who presented to our institution with high oxygen requirement. He had bilateral pneumonia and elevated interleukin levels. With time, his condition started deteriorating and his oxygen requirement progressively increased. In view of increased oxygen requirement, a high-flow nasal cannula (HFNC) was used initially. As the patient was unable to maintain peripheral oxygen saturation with HFNC, there was an imminent need for endotracheal intubation. However, a single intravenous use of $400 \mathrm{mg}$ of tocilizumab decreased the oxygen requirement, and the need for intubation 
was avoided. A similar case was described in the United Kingdom where the use of tocilizumab avoided the need for intubation [17].

\section{Conclusions}

The severity of COVID-19 is associated with the increased levels of pro-inflammatory cytokines including IL-6. Blockade of the inflammatory cascade has led to better outcomes in severe cases of COVID-19. Use of tocilizumab early in the course of illness might lead to improvement of the patient and avoid the need for endotracheal intubation.

\section{Additional Information \\ Disclosures}

Human subjects: Consent was obtained or waived by all participants in this study. Conflicts of interest: In compliance with the ICMJE uniform disclosure form, all authors declare the following: Payment/services info: All authors have declared that no financial support was received from any organization for the submitted work. Financial relationships: All authors have declared that they have no financial relationships at present or within the previous three years with any organizations that might have an interest in the submitted work. Other relationships: All authors have declared that there are no other relationships or activities that could appear to have influenced the submitted work.

\section{Acknowledgements}

We would like to express our sincere gratitude to Dr. Dhan Shrestha for his unconditional support in our projects.

\section{References}

1. Mehta P, McAuley DF, Brown M, Sanchez E, Tattersall RS, Manson JJ: COVID-19: consider cytokine storm syndromes and immunosuppression. Lancet. 2020, 395:1033-4. 10.1016/S0140-6736(20)30628-0

2. Kaur S, Bansal Y, Kumar R, Bansal G: A panoramic review of IL-6: structure, pathophysiological roles and inhibitors. Bioorg Med Chem. 2020, 28:115327. 10.1016/j.bmc.2020.115327

3. Del Valle DM, Kim-Schulze S, Huang HH, et al.: An inflammatory cytokine signature predicts COVID-19 severity and survival. Nat Med. 2020, 26:1636-43. 10.1038/s41591-020-1051-9

4. Fu B, Xu X, Wei H: Why tocilizumab could be an effective treatment for severe COVID-19? . J Transl Med. 2020, 18:164. 10.1186/s12967-020-02339-3

5. Xu X, Han M, Li T, et al.: Effective treatment of severe COVID-19 patients with tocilizumab . Proc Natl Acad Sci U S A. 2020, 117:10970-5. 10.1073/pnas.2005615117

6. Huang C, Wang Y, Li X, et al.: Clinical features of patients infected with 2019 novel coronavirus in Wuhan, China. Lancet. 2020, 395:497-506. 10.1016/S0140-6736(20)30183-5

7. Yuan J, Zou R, Zeng L, et al.: The correlation between viral clearance and biochemical outcomes of 94 COVID-19 infected discharged patients. Inflamm Res. 2020, 69:599-606. 10.1007/s00011-020-01342-0

8. Gupta S, Wang W, Hayek SS, et al.: Association between early treatment with tocilizumab and mortality among critically ill patients with COVID-19. JAMA Intern Med. 2021, 181:41-51. 10.1001/jamainternmed.2020.6252

9. Gordon AC, Mouncey PR, Al-Beidh F, et al.: Interleukin-6 receptor antagonists in critically ill patients with Covid-19. N Engl J Med. 2021, 384:1491-502. 10.1056/NEJMoa2100433

10. Salama C, Han J, Yau L, et al.: Tocilizumab in patients hospitalized with Covid-19 pneumonia . N Engl J Med. 2021, 384:20-30. 10.1056/NEJMoa2030340

11. Stone JH, Frigault MJ, Serling-Boyd NJ, et al.: Efficacy of tocilizumab in patients hospitalized with Covid-19 . N Engl J Med. 2020, 383:2333-44. 10.1056/NEJMoa2028836

12. Salvarani C, Dolci G, Massari M, et al.: Effect of tocilizumab vs standard care on clinical worsening in patients hospitalized with COVID-19 pneumonia: a randomized clinical trial. JAMA Intern Med. 2021, 181:24-31. 10.1001/jamainternmed.2020.6615

13. Lan SH, Lai CC, Huang HT, Chang SP, Lu LC, Hsueh PR: Tocilizumab for severe COVID-19: a systematic review and meta-analysis. Int J Antimicrob Agents. 2020, 56:106103. 10.1016/j.ijantimicag.2020.106103

14. Cortegiani A, Ippolito M, Greco M, et al.: Rationale and evidence on the use of tocilizumab in COVID-19: a systematic review. Pulmonology. 2021, 27:52-66. 10.1016/j.pulmoe.2020.07.003

15. Coronavirus (COVID-19) update: FDA authorizes drug for treatment of COVID-19 . (2021). Accessed: September 5, 2021: https://www.fda.gov/news-events/press-announcements/coronavirus-covid-19-updatefda-authorizes-drug-treatment-covid-19.

16. RECOVERY Collaborative Group: Tocilizumab in patients admitted to hospital with COVID-19 (RECOVERY): a randomised, controlled, open-label, platform trial. Lancet. 2021, 397:1637-45 10.1016/S0140-6736(21)00676-0

17. Gentile G, Davies R, Manfreda VM, Ul Abideen Z: Successful treatment of severe COVID-19 pneumonia and hyperinflammatory syndrome with tocilizumab. BMJ Case Rep. 2021, 14:e238210. 10.1136/bcr-2020-238210 